\title{
NOTIFICAÇÃO DE INTOXICAÇÃO POR AGROTÓXICOS: DESAFIOS PARA A ENFERMAGEM NO OESTE DO PARANÁ
}

\author{
Juliane Vanderlinde Hort ${ }^{1}$ \\ Alvori Ahlert ${ }^{2}$
}

\begin{abstract}
Resumo: Os agrotóxicos podem originar intoxicações agudas, subagudas e crônicas, desencadeando uma grave questão de saúde pública no Brasil e no oeste do Paraná, região de intenso uso de agrotóxicos. Buscando como objetivos fazer o levantamento de informações para verificar dados sobre o Sistema de Informação de Agravos de Notificação (SINAN), Intoxicação Exógena/Agrotóxicos, este documento traz resultados de uma pesquisa quantitativa realizada com profissionais enfermeiros das Unidades Básicas de Saúde e Unidades de Pronto Atendimento da $20^{a}$ regional da Saúde de Toledo - PR com auxílio de questionário. Ao confrontar dados, percebe-se a existência de prováveis subnotificações de intoxicações por parte da equipe de saúde. Viu-se também a necessidade de atualizar os profissionais em relação ao correto preenchimento e conhecimento dos agravos em saúde relacionados aos agrotóxicos. Conclui-se que existe a falta de suporte teórico e padronização adequada na área de saúde que favorecem o exercício profissional imperito, negligente e até imprudente, cujos resultados podem gerar danos à clientela e problemas legais e éticos aos profissionais da saúde.
\end{abstract}

Palvaras-chave: Agrotóxicos, Intoxicações, Vigilância em Saúde, Enfermagem.

\section{NOTIFICATION OF INTOXICATION BY PESTICIDES: CHALLENGES FOR NURSING IN THE WEST OS PARANÁ}

\begin{abstract}
Pesticides can cause acute, subacute and chronic intoxications, triggering a serious public health issue in Brazil and western Paraná, a region of intense use of pesticides. Seeking to collect information to verify the effectiveness of the Information Brasilian System for Notifiable Diseases (SINAN), Exogenous Intoxication / Pesticides, this document presents the results of a survey conducted with professional nurses from the Basic Health Units and Emergency Care Units of the 20th regional health office of Toledo-PR/BR using questionary. When confronting data, it is possible to perceive the existence of probable underreporting of intoxications by the health team. There was also a need to update professionals in relation to the correct filling and knowledge of health problems related to pesticides. It is concluded that there is a lack of theoretical support and adequate standardization in the health area that works in favor of the imperious, negligent and even imprudent professional exercise, which results can cause damage to the clientele and legal and ethical problems to the health professionals.
\end{abstract}

Keywords: Pesticides, Intoxications, Health Surveillance, Nursing.

\section{NOTIFICACIÓN DE INTOXICACIÓN POR PLAGUICIDAS: DESAFIOS PARA ENFERMERÍA EM EL OESTE DO PARANÁ}

\begin{abstract}
Resumen: Los pesticidas pueden causar intoxicaciones agudas, subagudas y crónicas, desencadenando un grave problema de salud pública en Brasil y el oeste de Paraná, una región de uso intensivo de pesticidas. Buscando recopilar información para verificar la efectividad del Sistema de Información brasileño para Enfermedades de Notificación (SINAN), Intoxicación Exógena / Pesticidas, este documento presenta los resultados de una encuesta realizada con enfermeras profesionales de las Unidades Básicas de Salud y Unidades de Atención de Emergencia del Regional de Salud de Toledo - PR utilizando un cuestionario. Al confrontar datos, es posible percibir la existencia de un subregistro probable de intoxicaciones por parte del equipo de salud. También era necesario actualizar a los profesionales en relación con el llenado correcto y el conocimiento de los problemas de salud relacionados con los pesticidas. Se concluye que existe una falta de apoyo teórico y una estandarización adecuada en el área de la salud que favorezca el ejercicio profesional imperioso, negligente e incluso imprudente, cuyos resultados pueden causar daños a la clientela y problemas legales y éticos a los profesionales de la salud.
\end{abstract}

Palavras clave: Pesticidas, intoxicaciones, vigilancia de la salud, enfermería.

\footnotetext{
${ }^{1}$ Doutoranda do Programa de Pós Graduação em Desenvolvimento Rural Sustentável - PPGDRS - UNIOESTE. Bolsista Fundação Araucária. julivanderlinde@ hotmail.com.

${ }^{2}$ Professor Associado da Universidade Estadual do Oeste do Paraná - UNIOESTE, no Programa de Pós-Graduação em Desenvolvimento Rural Sustentável - PPGDRS. alvoriahlert@yahoo.com.br.
} 


\section{Introdução}

Introduzidos no campo na década de 1930, o uso dos agrotóxicos foi intensificado a partir da Segunda Guerra Mundial. Máquinas e produtos químicos utilizados na guerra passaram a ser aplicados na agricultura e chegaram ao Brasil a partir dos anos 1950, dando início ao processo de modernização da agricultura tradicional, chamada de Revolução Verde. Estas novas tecnologias, intensificadas no final dos anos 1960 transformaram totalmente as formas de produzir e viver dos agricultores (LONDRES, 2011; GORGEN, 2004).

Graças à biotecnologia a produção de alimentos cresceu muito significativamente. A Revolução Verde mudou o cenário das lavouras a nível mundial, e igualmente travou um dos maiores embates ideológicos dentro da bioética: a utilização de agrotóxicos e as suas contaminações. Com o discurso de que a fome no mundo seria solucionada, a artificialização do modo de produção alimentar trouxe consigo uma série de problemas ambientais e de saúde pública (MELLO, 2003).

Durante a década de 1970 se completou o pacote de insumos químicos, com adubos, inseticidas, fungicidas e herbicidas. Após as duas grandes guerras mundiais, a indústria química, fabricante de venenos, encontrou na agricultura um novo mercado para os seus produtos. Políticas foram implementadas em todo o mundo com o objetivo de assegurar este mercado e promover a sua expansão do uso de agrotóxicos (MACHADO, 2007).

No Brasil, em junho de 2018, foi aprovado em uma comissão da câmara dos deputados, o Projeto de Lei (PL) $n^{\circ} 6.299 / 2002$, que propõe a alteração dos artigos $3^{\circ}$ e $9^{\circ}$ da Lei $n^{\circ} 7.802$, de 11 de julho de 1989, e que repercutiu nacionalmente gerando inúmeros debates e questionamentos por parte da sociedade e de instituições governamentais. O PL propôs modificar o sistema de registro de agrotóxicos, seus componentes e afins e trouxe discussões sobre temas importantes no que diz respeito às leis até então vigentes sobre o uso de agrotóxicos. Uma das primeiras colocações do projeto é a alteração do nome agrotóxico para defensivo agrícola, ou defensivo fitossanitário. Também dentro do PL estariam ocorrendo alterações dos órgãos responsáveis pela aprovação do agrotóxico, isentando Agência Nacional de Vigilância Sanitária (ANVISA) e o Ministério da Saúde da função ficando apenas o Ministério da Agricultura responsável pelas licenças sobre a comercialização e uso de agrotóxicos. A nova proposta também envolveu a questão de licenças temporárias para comercialização e uso de agrotóxicos, objetivando assim a desburocratização sobre o uso dos venenos (NISHIMORI, 2018). 
No início de 2019, novos registros de agrotóxicos pouco, moderadamente ou altamente tóxicos foram liberados. No mês de janeiro do corrente ano, quarenta novos produtos receberam permissão para entrar no mercado. Um dos agrotóxicos liberados, de nome Sulfoxaflor, já foi motivo de discussão nos Estados Unidos devido ao extermínio de abelhas. Metomil, um ingrediente ativo usado em agrotóxicos, altamente tóxico, indicado para culturas como algodão, batata, soja, couve e milho também, consta nos insumos liberados. Quatro produtos foram classificados como "altamente tóxicos" e danosos ao meio ambiente, e cerca de metade são "perigosos", segundo a classificação oficial (GRIGORI, 2019).

Um mês após a primeira liberação, em fevereiro de 2019 o Diário da União deferiu o registro de novos agrotóxicos para diversas culturas, como algodão, soja, milho, tomate, feijão, citrus, manga, melão e outros. Dos 29 nomes deferidos, dez são classificados como "medianamente tóxicos", e dez, de "alta toxicidade". Todos são considerados "produtos muito perigosos ao meio ambiente". No decorrer do ano de 2019, agrotóxicos mais modernos e genéricos foram liberados com o objetivo de fazer a "fila andar" aprovando novas moléculas, menos tóxicas e mais ambientalmente corretas (BRASIL/MAPA, 2019; BRASIL/ IMPRENSA NACIONALa, 2019; BRASIL/IMPRENSA NACIONALb, 2019).

Apesar do discurso promissor em criar um veneno ambientalmente correto, há meio século, numa atitude precursora, ao levantar fortes indagações sobre os impactos dos insumos químicos na acelerada expansão do desenvolvimento capitalista sobre o campo e a vida na terra, Carson (2010) alertou sobre a complexidade e a delicadeza das inter-relações ecológicas feridas pelos agrotóxicos e suas prováveis consequências. Desde então, agravos em saúde relacionados direta e indiretamente a agrotóxicos vêm sendo relatados em estudos, pesquisas e empiricamente por agricultores e trabalhadores rurais.

Uma intoxicação por agrotóxicos pode ter características agudas, subagudas e crônicas. As características da intoxicação agudam são o rápido surgimento de sintomas, imediatamente ou algumas horas após a exposição ao veneno. Trata-se de uma intoxicação de caráter ocupacional. Ocorre normalmente por um curto período de exposição, porém, com doses elevadas de produtos muito tóxicos. Os casos que chegam a ser notificados na Saúde Pública são, geralmente, desta categoria. Em relação aos seus efeitos no organismo humano, estes podem ser dores de cabeça, náuseas, vômitos, dificuldades respiratórias, fraqueza, salivação, cólicas abdominais, tremores, confusão mental, convulsões, entre outros (CARNEIRO, 2015; PIGNATTI, 2012).

As intoxicações agudas são as evidências mais visíveis do impacto direto à saúde do 
trabalhador. De acordo com o Ministério da Saúde, anualmente ocorrem mais de 400 mil contaminações por agrotóxicos, resultando em cerca de 4 mil mortes por ano (CARNEIRO, 2015).

A intoxicação subaguda ou sobreaguda advém da exposição moderada ou pequena a produtos de alta ou média toxicidade cujos efeitos podem aparecer em alguns dias ou semanas. É caracterizada também como uma intoxicação de origem alimentar ou da água, e pode causar dores de cabeça, fraqueza, mal-estar, dor de estomago e sonolência (CARNEIRO, 2015; PIGNATTI, 2012; RIGOTTO et al., 2010).

Uma intoxicação crônica consiste em uma forma de contaminação de caráter ambiental. Os efeitos crônicos podem ocorrer meses, anos ou décadas após a exposição ao agrotóxico, desenvolvendo no homem tumores, cânceres, malformação congênita e distúrbios nos sistemas imunológico, neurológico, hematopoiético, respiratório, cardiovascular, geniturinário, gastrintestinal, hepático, reprodutivo e endócrino. São sintomas subjetivos e de difícil diagnóstico, ainda, muitas vezes, irreversíveis (DUTRA; FERREIRA, 2017; HORT, 2016; CARNEIRO, 2015; MASCARENHA; PESSOA, 2013; PIGNATTI, 2012; LONDRES, 2011).

O estado do Paraná é um dos estados brasileiros com maior uso e comercialização de agrotóxicos e chega a consumir até seis vezes mais que a média brasileira em litros de agrotóxicos por hectare de produção (SIMÕES; 2018; HORI, 2014).

Considerando a grave questão de saúde apresentada em relação às intoxicações decorrentes do uso de agrotóxicos, o presente artigo trouxe o levantamento de informações para verificar a eficácia da vigilância em saúde realizada através do Sistema de Informação de Agravos de Notificação (SINAN)/ Intoxicação Exógena/Agrotóxicos na Saúde Pública.

A ficha de Intoxicação Exógena do Sinan é um documento complexo e não exclusivo para agrotóxicos, com campos para preenchimento dos dados do paciente e a forma de contaminação, que podem diferenciar em drogas, medicamentos, produtos veterinários, bebidas e alimentos, produtos cosméticos, plantas tóxicas, raticidas, produtos de limpeza doméstica, e tipos de agrotóxico (doméstico ou agrícola), todos na mesma ficha: contaminação exógena. A intoxicação por agrotóxicos está presente na Lista de Notificação Compulsória (LNC) do Sistema Único de Saúde (SUS), e seu encaminhamento deve ocorrer semanalmente. O documento do Sinan deve ser preenchido toda vez que o paciente der entrada no sistema de saúde apresentando sinais e sintomas de intoxicação por químicos exógenos (BRASIL/VSPEA, 2016).

O Ministério da Saúde chama a atenção para as regiões do país mais afetadas pelo uso indiscriminado de agrotóxicos e suas consequências. O oeste do Paraná é umas das regiões citadas 
pelo Relatório Nacional de Vigilância de Populações Expostas aos Agrotóxicos (VSPEA) devido ao uso massivo de agrotóxicos, promovendo a contaminação dos seres vivos, do solo e da água (BRASIL/SINANWEB, 2019; BRASIL/MS/VSPEA, 2018; BRASIL/MS/VSPEA, 2016).

Em relação à alteração do padrão de potabilidade para os parâmetros de agrotóxicos para consumo humano na água, dos 43 municípios paranaenses monitorados e citados no VSPEA, oito pertencem ao oeste do Paraná. O estado permaneceu em destaque no último estudo divulgado em abril de 2019, onde dados do Ministério da Saúde, Sistema de Informação de Vigilância da Qualidade da Água para Consumo Humano (SISAGUA), revelaram que 326 municípios paranaenses, de um total de 399, apresentaram 100\% dos agrotóxicos pesquisados no estudo, deixando o estado do Paraná apenas atrás do estado de São Paulo na análise de água a nível Nacional (ARANHA; ROCHA, 2019; BRASIL/MS/VSPEA, 2016).

O estado do Paraná é um dos estados brasileiros com maior uso e comercialização de agrotóxicos. Os dados demonstram que a utilização de agrotóxicos para o controle de pragas, doenças e ervas daninhas mais que dobrou em dez anos, colocando o estado do Paraná em destaque nesta utilização. O desconhecimento da grave situação em saúde pública, conforme apontado no estudo de Simões (2018), leva a piora do quadro, sendo de extrema importância a conscientização e divulgação de dados de ingredientes ativos e suas consequências.

O Paraná igualmente é um dos estados que mais registrou intoxicações por agrotóxicos no Sinan (PARANÁ, 2013).

Em junho de 2017 foi publicado o estudo de Dutra e Ferreira, cujo tema envolveu a “Associação entre malformações congênitas e a utilização de agrotóxicos em monoculturas no Paraná, Brasil". O estudo envolveu municípios do Oeste do Paraná, e colocou como um de seus resultados as seguintes considerações:

O controle efetivo da exposição a esses pesticidas é muito pequeno e escasso no cenário brasileiro. Os dados referentes ao uso dos produtos não são sistematizados em bancos de dados informatizados para a grande maioria dos estados do País. Isso dificulta a mensuração do impacto da exposição ambiental desses produtos sofrida pela população. Além disso, o lobby exercido pelas grandes corporações impede, quase sempre, o acesso à informação (DUTRA; FERREIRA, 2017, p. 250).

O lobby do agronegócio no Brasil é institucionalizado e atua no Congresso a partir da face mais organizada da bancada ruralista em Brasília, a Frente Parlamentar da Agropecuária. Adotada como instrumento organizativo desde a sua formalização, a bancada ruralista tem acumulado poder para derrubar e manter leis nacionais. Ainda, expoentes da indústria e setores financeiros possuem 
seus braços no setor agropecuário e mantêm um íntimo relacionamento com os donos da terra (SANTOS; GLASS, 2018).

Outra característica do estado do Paraná, é que este congrega empresas formuladoras de agrotóxicos e participa de forma significativa na pecuária nacional. Entre os estados brasileiros com maior consumo de agrotóxicos o estado do Paraná representa 14,3\% desse quantitativo. A área de plantio para a produção de grãos no Paraná aumentou em 39\% entre os anos de 2000 e 2014 (5,9 mil hectares para 8,2 mil hectares), e de forma discrepante o consumo de agrotóxicos aumentou em $111 \%$ (27,6 toneladas para 57,8 toneladas) no mesmo período (SANTOS; GLASS, 2018).

Esse contexto traz destaque às malformações congênitas evidenciadas no estado do Paraná, nas cidades de Cascavel e Francisco Beltrão, associadas à quantidade de agrotóxicos utilizados, discutidas no estudo de Dutra e Ferreira. Cascavel, cidade vizinha à região Oeste do Paraná, ultrapassou a marca de 5000 toneladas de agrotóxicos utilizados nos anos 2014 e 2015, ficando em primeiro lugar nos municípios paranaenses. Toledo, município da região oeste, ficou em terceiro lugar, com mais de 3000 toneladas de uso, sendo que este representa apenas metade da população de Cascavel (SIMÕES, 2018; DUTRA; FERREIRA, 2017; BRASIL/IBGE, 2010).

Segundo informe epidemiológico da $20^{\mathrm{a}}$ Regional de Saúde de Toledo - PR a Vigilância em Saúde de Populações Expostas a Contaminantes Químicos, objetiva o desenvolvimento de ações de vigilância em saúde de forma a adotar medidas de promoção, prevenção contra doenças e agravos, e atenção integral à saúde das populações expostas a contaminantes químicos (BRASIL/SCGVE, 2017).

Em novembro de 2017 o informe epidemiológico da 20a Regional de Saúde de Toledo - PR, cuja fonte é o preenchimento do Sinan, publicou que de 2012 a novembro de 2017 (5 anos) foram registradas apenas 75 intoxicações por agrotóxicos: Origem agrícola, 45 intoxicações; Agrotóxico doméstico: 28 casos registrados; e agrotóxico de saúde pública: 2 casos. Esse dado apontaria para uma média de 15 intoxicações por ano, para toda região da $20^{a}$ Regional do Paraná, que soma dezoito municípios do Oeste do Paraná (BRASIL/SCGVE, 2017). Se analisarmos, 75 casos de intoxicação é proporcionalmente inferior ao apontado no período de 2007 a 2011 (4 anos), onde o Sinan registrou quase sete mil ocorrências de intoxicação por agrotóxicos em todo o estado do Paraná, representando uma média anual próxima de duas mil intoxicações.

No Relatório Nacional de Vigilância em Saúde de Populações Expostas a Agrotóxicos (VSPEA) de 2016 consta a informação de que os estados que mais notificaram casos de intoxicação exógena por agrotóxicos, no período de 2007 a 2014 (7 anos), foi São Paulo com 12562 casos e em 
segundo lugar, o Paraná, com quase 11 mil casos, média anual de 1567 intoxicações (PARANÁ, 2013).

Mesmo sendo um dado referente a todo o estado, e semelhante ao apresentado pelo VSPEA Paraná, a diferença de casos notificados na ficha Sinan Intoxicação Exógena difere muito da média esperada comparando os municípios da $20^{\text {a }}$ Regional de Saúde do Oeste do Paraná com o restante do Estado, conforme esquematizado na tabela 1:

\begin{tabular}{|c|c|c|c|}
\hline Documentos analisados & VSPEA Paraná, 2013 & VSPEA Brasil, 2016 & $\begin{array}{l}\text { Informe Epidemiológico da } \\
20^{\mathrm{a}} \text { Regional de Saúde } \\
\text { Toledo, } 2017\end{array}$ \\
\hline Período da coleta de dados & $\begin{array}{l}2007 \text { a } 2011 \\
(4 \text { anos })\end{array}$ & $\begin{array}{l}2007 \text { a } 2014 \\
\text { (7 anos) }\end{array}$ & $\begin{array}{l}2012 \text { a } 2017 \\
(5 \text { anos })\end{array}$ \\
\hline $\begin{array}{l}\text { Intoxicações por ano/ } \\
\text { Total de municípios. }\end{array}$ & $\begin{array}{l}1735 \text { intoxicações no estado } \\
\text { do Paraná/ } \\
399 \text { municípios. }\end{array}$ & $\begin{array}{l}1567 \text { intoxicações no estado } \\
\text { do Paranál } \\
399 \text { municípios. }\end{array}$ & $\begin{array}{l}15 \text { intoxicações na } 20^{\mathrm{a}} \text { Regional } \\
\text { de Toledo/ } \\
18 \text { municípios. }\end{array}$ \\
\hline $\begin{array}{l}\text { Média de intoxicação anual } \\
\text { por município }\end{array}$ & 5 intoxicações & 4 intoxicações & 0,8 intoxicações \\
\hline
\end{tabular}

Fonte: BRASIL, 2017; BRASIL, 2016; PARANÁ, 2013.

Durante a reunião do Grupo de Trabalho (GT) da $20^{\text {a }}$ Regional, realizado em 25 de setembro de 2018, representantes afirmaram que a 20ª Regional de Saúde de Toledo trata-se da pior regional a notificar casos de intoxicação por agrotóxicos em todo estado do Paraná, corroborando para o resultado encontrado na bibliografia. No mês de agosto de 2018, a informação preliminar era de apenas três casos notificados para todos os 18 municípios.

\section{Materiais e Métodos}

Como ferramentas metodológicas foi aplicado um questionário on-line disponibilizado via e-mail às unidades básicas de saúde (UBS) e pronto atendimento (UPA) da $20^{\text {a }}$ Regional de Saúde de Toledo, sendo então, a pesquisa delimitada dentro dos dezoito municípios pertencentes à $20^{\mathrm{a}}$ Regional Toledo. Todos os municípios estão geograficamente localizados no Oeste do Paraná, região citada como de uso intenso de agrotóxicos.

O questionário completo teve sua aprovação junto ao comitê de ética em pesquisa (CEP) com seres humanos da Unioeste, com número do Parecer: 2.989.382, cujo processo de submissão se deu através da Plataforma Brasil, pertencente ao Ministério da Saúde. Juntamente com o questionário, considerando as questões éticas envolvidas na pesquisa, foi enviado um Termo de Consentimento Livre esclarecido com informações referentes a pesquisa, como seus objetivos, finalidades e contato dos pesquisadores para maiores esclarecimentos. 
Para Gil (2002), a pesquisa de campo utiliza técnicas padronizadas de coleta de dados, tais como o questionário e a observação sistemática. A pesquisa de campo é caracterizada pelas investigações em que se realiza coleta de dados junto a pessoas. Através do questionário, na pesquisa quantitativa, é possível quantificar os dados com amostras grandes e representativas da população, no caso, os enfermeiros, atuantes na saúde pública da $20^{\mathrm{a}}$ Regional de Toledo - PR (GERHARDT; SILVEIRA, 2009; GIL, 2002; GIL, 1999).

O questionário aplicado aos profissionais enfermeiros das Unidades Básicas de Saúde (UBS) e Unidades e Pronto Atendimentos (UPA) da 20ª regional da Saúde de Toledo - PR da pesquisa, abrangeu os seguintes municípios: Assis Chateaubriand, Diamante D'Oeste, Entre Rios do Oeste, Guaíra, Marechal Cândido Rondon, Maripá, Mercedes, Nova Santa Rosa, Ouro Verde do Oeste, Palotina, Pato Bragado, Quatro Pontes, Santa Helena, São José das Palmeiras, São Pedro do Iguaçu, Terra Roxa, Tupãssi e Toledo. Pertencem a 20a Regional de Toledo um total de 116 UBS e três UPAs. As três unidades de pronto atendimento estão presentes apenas nos municípios de Guaíra, Marechal C. Rondon e Toledo.

O presente estudo recorreu a uma amostragem probabilística, aleatória, onde foram selecionados os elementos (população: todos os enfermeiros da UBS e UPAs da 20a Regional de Toledo - PR) admitindo que estes possam de alguma forma, representar (amostra) o universo do estudo (SARAIVA, 2015; GIL, 1999).

Sendo assim, aplicando a fórmula e variáveis com auxílio da planilha do Excel, em cálculos com a confiança dos dados variando $90 \%$ a $95 \%$ e margens de erro de $5 \%$ a $10 \%$, em uma população de $119(\mathrm{~N})$, o resultante para a amostra (n) permanece com valores entre 35 a 40. Estabeleceu-se assim a quantidade de questionários necessários objetivando um estudo confiável dentro das análises quantitativas. Como efeito, foram construídos gráficos com frequências relativas à população total do estudo. Foram recebidos 36 questionários $(n=36)$, com pelo menos um questionário por município, dos 18 municípios da 20ª Regional de Saúde de Toledo.

A equipe de enfermagem coordenada pelo enfermeiro exerce papel primordial na assistência integral ao cliente/paciente, sendo a UBS e as UPAs, as portas de entrada para o Sistema Único de Saúde (SUS). É nestes estabelecimentos que o indivíduo que sofreu com intoxicações por agrotóxicos buscará auxílio para realizar o tratamento, integrando-se ao público assistido pelo SUS. Os profissionais que atuam nesse âmbito são médicos, psicólogos, agentes comunitários de saúde, nutricionistas, dentistas, recepcionistas, equipe de apoio, motoristas e a equipe de enfermagem: enfermeiros e técnicos de enfermagem. 
Compreendendo a qualidade da atenção e gestão o Sistema único de Saúde (SUS), este deve compreender os princípios da integralidade, universalidade, equidade e participação social:

Deve ser operacionalizado por meio do exercício de práticas de cuidado e de gestão democráticas e participativas, sob a forma de trabalho em equipe dirigido às populações de territórios definidos [...]. A atenção básica deve, ainda, utilizar tecnologias de cuidado complexas e variadas para auxiliar no manejo das demandas e necessidades de saúde de maior frequência e relevância em seu território, observando critérios de risco, vulnerabilidade e resiliência e o imperativo ético de que toda demanda, necessidade de saúde ou sofrimento devem ser acolhidos (GALAVOTE, H.S. et al, 2016, p. 91).

A enfermagem tem íntima ligação com seus clientes/pacientes, pois o profissional da área desenvolve um papel de essencial importância na modalidade de assistência à saúde. Para que essa conexão seja feita promovendo a saúde do indivíduo o profissional de Enfermagem deve fazer um diagnóstico situacional, classificando potencialidades e dificuldades.

Essa ação corresponde a um dos objetivos primordiais da atenção básica, principalmente nas UBS: a "longitudinalidade", que se traduz em acompanhar o indivíduo e seus núcleos de convívio de forma integral e humanitária, com uso racional dos recursos assistenciais. Para guiar esse trabalho e manter um padrão de qualidade por todo o país, o enfermeiro tem à disposição protocolos, guias e manuais a nível ministerial e estadual, onde são citadas as funções de todas as categorias da equipe de (PEREIRA, 2016, p.1).

A área da Enfermagem é responsável por trabalhar com a vinculação e proximidade da comunidade, alerta aos problemas e anseios dessa população. O enfermeiro na atenção básica é um dos elos da comunidade com o serviço de saúde.

\section{Resultados e Discussão}

O questionário abordou o preenchimento da ficha do Sinan Intoxicação Exógena/ Agrotóxicos. Características e ações desenvolvidas pelos enfermeiros foram questionadas relacionadas às notificações através do Sinan. Conforme organizado na Tabela 2, todos profissionais entrevistados conhecem o sistema de notificação, e cerca de $90 \%$ utilizou o sistema nos últimos seis meses. Apenas $17 \%$ utilizaram para notificações de intoxicação por agrotóxicos nesse período.

Tabela 2 - Ações e características desenvolvidas pelos enfermeiros entrevistados em relação ao Sistema de Agravos de Notificação (Sinan) e o tema agrotóxicos:

\begin{tabular}{lc}
\hline Característica ou Ação & Enfermeiros que responderam positivamente (\%) \\
\hline Conhece o Sinan/SUS & $100 \%$ \\
Usou a ficha Sinan nos últimos 6 meses & $90 \%$ \\
\hline
\end{tabular}


Usou a ficha para Intoxicação Exógena do Sinan

Usou a ficha para Intoxicação Exógena/ Agrotóxico do Sinan

Considera simples o preenchimento da ficha do Sinan

Participou de Capacitação sobre o tema Intoxicação por Agrotóxicos

Fonte: Acervo dos pesquisadores, 2020.
$56 \%$

$17 \%$

$60 \%$

$52 \%$

O fato de apenas $17 \%$ terem usado a ficha de intoxicação exógena do Sinan pode estar relacionado à complexidade do documento, não exclusivo para agrotóxicos, com campos para preenchimento de dados do paciente e a forma de contaminação, que podem diferenciar em drogas, medicamentos, produtos veterinários, bebidas e alimentos, produtos cosméticos, plantas tóxicas, raticidas, produtos de limpeza doméstica e tipos de agrotóxico (doméstico ou agrícola), todos na mesma categoria: contaminação exógena.

Se ocorrer a contaminação por agrotóxicos, é possível preencher campos específicos sobre a forma de contaminação e via de entrada no organismo, bem como outros dados para serem preenchidos. A ficha de notificação por Intoxicação Exógena deve ser preenchida toda vez que o paciente der entrada no sistema de saúde pública (Unidade Básica de Saúde ou Pronto Atendimento) apresentado suspeita de intoxicação, com sinais e sintomas de intoxicação por químicos exógenos.

Sobre a circunstância em que é realizada a notificação no Sinan Intoxicação Exógena por Agrotóxicos, obtiveram-se os dados, representados no Gráfico 1, onde $90 \%$ dos enfermeiros realizam a notificação apenas em caso de suspeita, cerca de $8 \%$ após diagnóstico médico, $2 \%$ apenas após exames complementares ao diagnóstico médico:

Gráfico 1 - Circunstância em que é realizada a notificação de intoxicação exógena na ficha do Sinan/SUS:

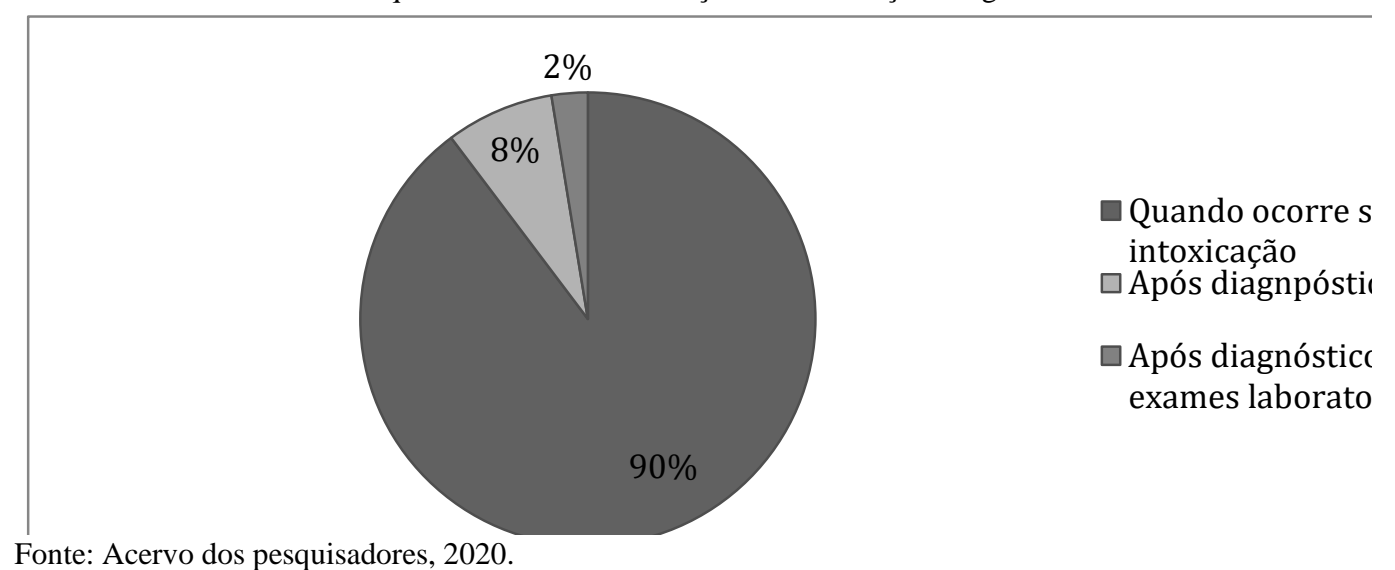

O preenchimento da ficha Sinan pode ocorrer mediante suspeita de intoxicação. No entanto, apenas após diagnóstico médico, com ou sem exames laboratoriais, é que a ficha poderá ser encaminhada. A enfermagem tem autonomia, assim como outros profissionais não médicos da 
atenção básica, para realizar um diagnóstico competente ao exercício de sua profissão. No caso do enfermeiro, um diagnóstico situacional, onde se suspeita da intoxicação por agrotóxicos. Após diagnóstico médico clínico, a ficha poderá ser encaminhada para o sistema de coleta de dados. O Sinan pode ser operacionalizado em seu nível administrativo mais periférico, ou seja, nas unidades de saúde, seguindo a orientação de descentralização do SUS. Grande parte das notificações são digitadas nas Secretarias municipais de saúde. Se o município não dispõe de computadores, os dados são incluídos no sistema nas regionais de Saúde (BRASIL/SINANWEB, 2020).

A Ficha Individual de Notificação (FIN) é preenchida pelas unidades assistenciais para cada paciente quando ocorre suspeita de problema de saúde de notificação compulsória ou de interesse nacional, estadual ou municipal. Esse instrumento deve ser encaminhado aos serviços responsáveis pela informação e/ou vigilância epidemiológica das Secretarias Municipais (SVS), que, por sua vez, repassam semanalmente os arquivos em meio magnético para as Secretarias Estaduais de Saúde (SES). No início de cada ano deve se estabelecer um cronograma de comunicação das SES com a SVS que deverá ocorrer quinzenalmente ao longo do ano (BRASIL/SINANWEB, 2020).

Em relação às capacitações, a partir do ano de 2019 iniciaram-se efetivamente as ações do VSPEA paranaense e da $20^{\mathrm{a}}$ Regional de Saúde de Toledo. Finalizado em 2018, o novo Plano Regional de Vigilância e Atenção à Saúde de Populações Expostas aos Agrotóxicos do Estado do Paraná, 2017 a 2019, foi organizado com ações estratégicas enviadas para avaliação do SESA (Secretaria de Saúde). Cada ação possui objetivos geral, específicos e com justificativa. Ainda possui um quadro com o detalhamento da ação, como a estratégia a ser adotada, a meta proposta, indicadores e recursos necessários, prazo, responsáveis e custos estimados. O mais novo documento auxiliar para os profissionais de saúde, desenvolvido pela SESA trata-se de uma Linha Guia de atenção às populações expostas aos agrotóxicos:

Após o lançamento da Portaria 2938/2012, pelo Ministério da Saúde, instituindo a Vigilância em Saúde de Populações Expostas a Agrotóxicos, a Secretaria de Estado da Saúde do Paraná elaborou e implantou o Plano Estadual de Vigilância das Populações Expostas aos Agrotóxicos 2013-2016, contendo 14 ações estratégicas. No início de 2017, durante a avaliação do Plano 2013-2016, somada à demanda crescente por oferta de serviços ou pontos de atenção, a SESA-PR optou por incluir a assistência à saúde nessa discussão, com foco na exposição e intoxicação por agrotóxico, surgindo o Plano Estadual de Vigilância e Atenção à Saúde das Populações Expostas Aos Agrotóxicos 2017-2019 (PEVASPEA-PR), com 20 ações estratégicas, cujo ineditismo é ter em seu escopo orientações à assistência na forma de uma Linha Guia. A concretização de uma Linha Guia subsidiará tecnicamente os profissionais da rede de atenção primária para o acolhimento, diagnóstico, tratamento, notificação e acompanhamento da saúde dos trabalhadores 
e população exposta aos efeitos agudos e crônicos dos agrotóxicos no Estado do Paraná (PARANÁ/SESA, 2018, p.5).

Para os entrevistados, a maior responsável pelo preenchimento da ficha do Sinan é a equipe de enfermagem, sendo que $44 \%$ das respostas indicam ser tarefa dos enfermeiros, seguido do técnico de enfermagem com $16 \%$ e o médico com 16\%. No entanto, uma porção representativa, $24 \%$, assinalou que todos profissionais da atenção básica são responsáveis pelo preenchimento, deixando registrada inclusive a opção "outro profissional", além das opções "enfermeiro, técnico de enfermagem, médico e farmacêutico", presentes no questionário. De acordo com a lei, a enfermagem não é exclusiva para o preenchimento da ficha. Recepção, transporte, consulta médica, vacina, atendimentos gerais, medicação, curativos e outros procedimentos, são realizados por uma equipe multidisciplinar, e o preenchimento da ficha Sinan não é diferente:

Segundo a Portaria MS n ${ }^{\circ} 1.271$, de 6 de junho de 2014, a intoxicação por agrotóxicos faz parte da Lista de Notificação Compulsória (LNC) do Sistema Único de Saúde (SUS) e deve ser notificada semanalmente por meio da ficha de intoxicações exógenas do Sistema de Informação de Agravos de Notificação (Sinan) por médicos, outros profissionais de saúde ou responsáveis pelos serviços públicos e privados de saúde que prestam assistência ao paciente; pelos responsáveis por estabelecimentos públicos ou privados educacionais, de cuidado coletivo, além de serviços de hemoterapia, unidades laboratoriais e instituições de pesquisa (...) A notificação deve ser imediata até 24 horas quando ocorrer acidente de trabalho grave, fatal e em crianças e adolescentes (BRASIL/VSPEA, 2016. p.15).

Assim, como em todas as instâncias de saúde, a atenção básica requer que o trabalho em equipe seja devotado, permitindo à enfermagem, muitas vezes sobrecarregada, o auxílio por outros profissionais.

Especificamente sobre agrotóxicos, dentro da educação continuada, seu cuidado, manuseio e graus de periculosidade, cerca de $80 \%$ dos profissionais responderam que não possuem conhecimento sobre esses temas. Destaca-se ser fundamental o enfermeiro ter conhecimento sobre o cuidado, manuseio e graus de periculosidade dos químicos utilizados pela comunidade. O enfermeiro tem acesso direto ao cliente através de consultas de enfermagens e procedimentos na atenção básica, bem como, na residência desses indivíduos, indiretamente através do trabalho dos Agentes Comunitárias de Saúde (ACS), ou diretamente em casos de procedimentos específicos do enfermeiro, que podem ser realizados na própria residência do paciente. É nestes momentos que o enfermeiro, conforme apreendido em sua formação, tem a oportunidade de trazer educação em saúde aos seus clientes, otimizando o tratamento, de forma holística e integral. Se a região de 
atuação do enfermeiro for agrícola, como o Oeste do Paraná, torna-se essencial esse conhecimento por parte desses profissionais.

De acordo com o Gráfico 2 a maioria dos entrevistados, $70 \%$ dos profissionais, assinalou que é necessária uma atualização em saúde para o preenchimento da ficha do Sinan, bem como educação para a importância da temática das intoxicações por agrotóxicos.

Gráfico 2 - Os profissionais enfermeiros elencaram a alternativa que mais lhes chamou atenção:

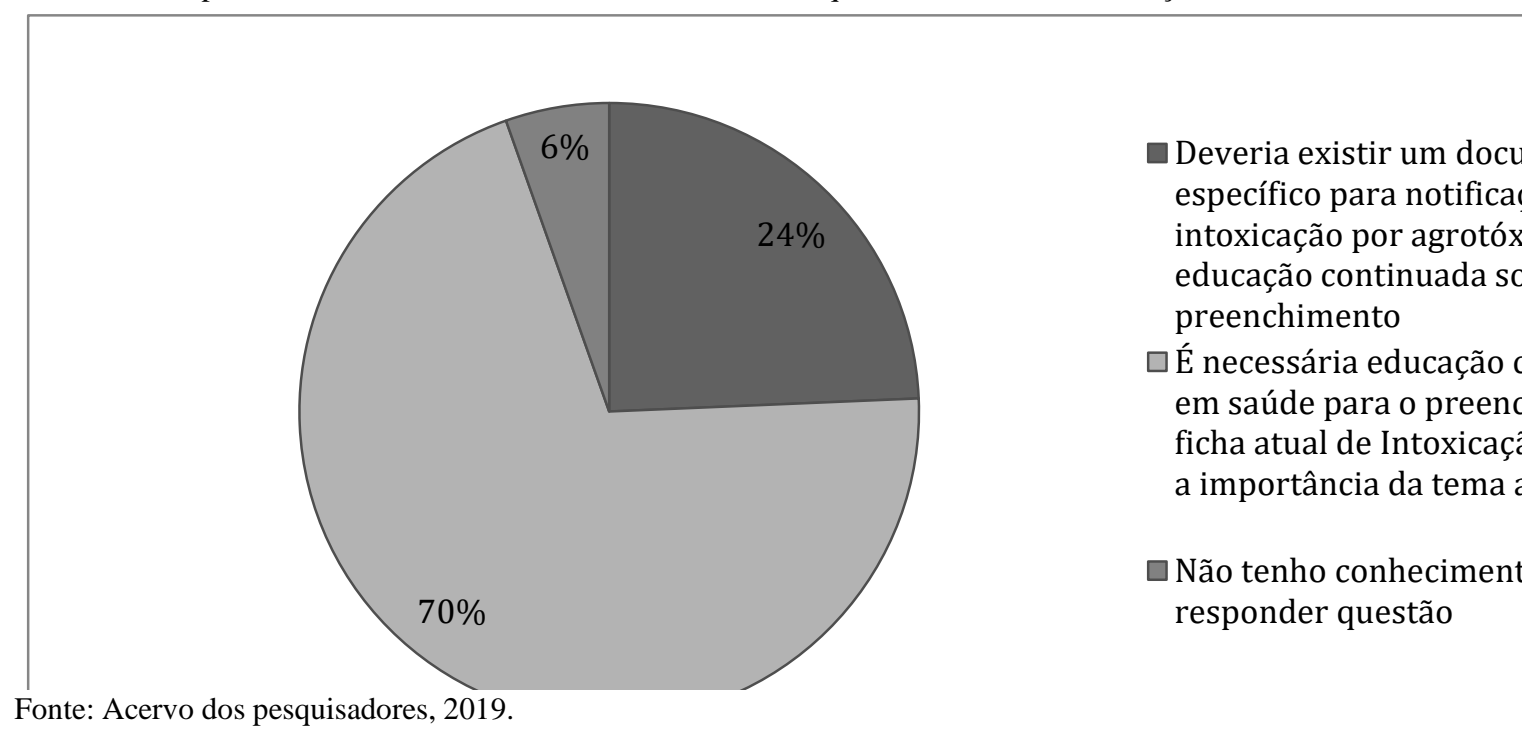

\section{Conclusões}

Concluímos que existe a falta de suporte teórico e padronização adequada na área de saúde concernente à intoxicação por agrotóxicos, o que favorece o exercício profissional imperito, negligente e até imprudente, cujos resultados podem gerar danos à clientela e problemas legais e éticos aos profissionais da saúde.

Apurou-se que o uso da ficha de notificação de Intoxicação Exógena do Sinan é burocrático. O preenchimento dificulta os registros em tempo hábil para a equipe de saúde, o que nos lança a hipótese da existência de subnotificações em casos relacionados com a contaminação por agrotóxicos não registrados na região de abrangência da $20^{a}$ Regional da Saúde do Estado do Paraná, dificultando, assim, as ações e promoções em saúde, o que também pode estar escamoteando os índices de intoxicação na referida região.

Diante dos dados apresentados por diferentes documentos de vigilância, leis atuais e respostas do questionário aplicado aos enfermeiros da $20^{\mathrm{a}}$ Regional de Saúde de Toledo - PR, fica evidente a importância da educação continuada para os profissionais de saúde relativo ao preenchimento correto e ativo da ficha Sinan Intoxicações Exógenas/ Agrotóxicos. 
É urgente a necessidade de implementar ações da vigilância e a instrução sobre o uso da Linha Guia, em saúde, para que, diante das intensas novas liberações de agrotóxicos, a região esteja melhor preparada para registro de dados mais representativos da eficiência da vigilância em saúde e preenchimento da ficha Sinan Intoxicação exógena/Agrotóxico.

Estes desafios são decorrentes dos resultados da pesquisa acima apresentada e socializados juntamente com os profissionais da área em favor de ações propostas pelo Plano Regional de Vigilância e Atenção à Saúde de Populações Expostas aos Agrotóxicos da $20^{\text {a }}$ Regional de Saúde Toledo, no Oeste do Estado do Paraná.

\section{Referências}

ARANHA, A. ROCHA, L. Coquetel perigoso Levantamento aponta que 1 a cada 4 cidades brasileiras tem água contaminada por 27 tipos de agrotóxicos. Repórter Brasil e Agência Pública. UOL Notícias. Abr. 2019 [acessado 2019 abr 16]. Disponível em: https://noticias.uol.com.br/reportagens-especiais/coquetel-com-agrotoxicos-esta-presente-na-aguade-1-a-cada-4-municipios\#coquetel-perigoso.

BRASIL/IBEGE. Instituto Brasileiro de Geografia e Estatística. IBGE. Censo Demográfico, 2010.

BRASIL/ IMPRENSA NACIONALa. Ato n. 10 de 18 de fevereiro de 2019. Ministério da Agricultura, Pecuária e Abastecimento/Secretaria de Defesa Agropecuária/Departamento de Sanidade Vegetal e Insumos Agrícolas/Coordenação-Geral de Agrotóxicos e Afins. Diário Oficial da União. 2019; 10-18 fev. Disponível em: http://www.in.gov.br/materia//asset_publisher/Kujrw0TZC2Mb/content/id/64365728/do1-2019-02-21-ato-n-10-de-18-defevereiro-de-2019-64365509. Acesso em 01 fev. 2020.

BRASIL/IMPRENSA NACIONALb. Ato n' 62, de 13 de setembro de 2019. Diário Oficial da União. Publicado em: 17/09/2019|Edição: 180 |Seção: 1 |Página: 4rgão: Ministério da Agricultura, Pecuária e Abastecimento/Secretaria de Defesa Agropecuária/Departamento de Sanidade Vegetal e Insumos Agrícolas/Coordenação-Geral de Agrotóxicos e Afins. Disponível em: http://www.in.gov.br/en/web/dou/-/ato-n-62-de-13-de-setembro-de-2019-216556339. Acesso 01 fev. 2020.

BRASIL/MAPA. Ministério da Agricultura, Pecuária e Abastecimento. Diário Oficial traz publicação de defensivos agrícolas, com genéricos e produtos mais modernos. 2019. Disponível em: http://www.agricultura.gov.br/noticias/diario-oficial-traz-publicacao-de-defensivos-agricolascom-genericos-e-produtos-mais-modernos. Acesso em 01 fev 2020.

BRASIL/MS/SCGVE. Ministério da Saúde. Secretaria de Saúde. Regionais SESA, 20a Regional RS Toledo - PR. Informe Epidemiológico Novembro de 2017. Governo do Estado do Paraná, 2017.

BRASIL/SINAN/WEB. Sistema de Informação de Agravos de Notificação/ Funcionamento Sinan. Atualizado em 21 de Jul 2017. Disponível em: http://portalsinan.saude.gov.br/funcionamentos. Acesso em: 01 fev 2020.

NISHIMORI L, relator. Projeto de lei $\mathbf{n}^{\mathbf{0}}$ 6.299, de 2002. Comissão especial destinada a proferir parecer ao Projeto de Lei $n^{\circ} 6299$, de 2002, do senado federal, que "altera os arts $3^{\circ}$ e $9^{\circ}$ da lei $n^{\circ}$ 7.802, de 11 de julho de 1989. Câmara dos Deputados, abr. 2018. Disponível em: 
https://www.camara.leg.br/proposicoesWeb/prop_mostrarintegra?codteor=1669849. Acesso 01 fev 2020.

BRASIL/MS/VSPEA. Ministério da Saúde. Secretaria de Vigilância em Saúde. Departamento de Vigilância em Saúde Ambiental e Saúde do Trabalhador. Agrotóxicos na ótica do Sistema Único de Saúde / Ministério da Saúde, Secretaria de Vigilância em Saúde, Departamento de Vigilância em Saúde Ambiental e Saúde do Trabalhador. - Brasília: Ministério da Saúde, 2018. 191p. Disponível em: http://bvsms.saude.gov.br/bvs/publicacoes/relatorio_nacional_vigilancia_populacoes_expostas_agr otoxicos.pdf. Acesso em $01 \mathrm{fev} .2020$.

BRASIL/MS/VSPEA. Ministério da Saúde. Secretaria de Vigilância em Saúde. Departamento de Vigilância em Saúde Ambiental e Saúde do Trabalhador. Agrotóxicos na ótica do Sistema Único de Saúde / Ministério da Saúde, Secretaria de Vigilância em Saúde, Departamento de Vigilância em Saúde Ambiental e Saúde do Trabalhador. - Brasília: Ministério da Saúde, 2016. 139p. Disponível em: http://bvsms.saude.gov.br/bvs/publicacoes/agrotoxicos_otica_sistema_unico_saude_v1_t.1.pdf.

Acesso em 01 fev. 2020.

CARSON, R. Primavera Silenciosa. Gaia Editora: 2010. 328 p.

CARNEIRO, F.F. organizador. DOSSIÊ ABRASCO: Um alerta sobre os impactos dos agrotóxicos na saúde. Rio de Janeiro: Expressão Popular; 2015.

DUTRA L. S., FERREIRA, A. P. Associação entre malformações congênitas e a utilização de agrotóxicos em Monoculturas no Paraná, Brasil. Revista Saúde Debate. 2017; 41(especial): 241253. Disponível em: http://www.scielo.br/pdf/sdeb/v41nspe2/0103-1104-sdeb-41-spe2-0241.pdf. Acesso em 1 fev. 2020.

GALAVOTE, H.S. et al. O trabalho do enfermeiro na atenção primária à saúde. Escola Anna Nery. v.20, n.1, p.90-98, 2016.

GIL, A. C. Como elaborar projetos de pesquisa. 4. ed. São Paulo: Atlas, 2002.

Gil A. C. Métodos e técnicas de pesquisa social. 5ed. São Paulo: Atlas, 1999.

GERHARDT, T. E. SILVEIRA, D.T. Métodos de pesquisa / [organizado por] Tatiana Engel Gerhardt e Denise Tolfo Silveira; coordenado pela Universidade Aberta do Brasil - UAB/UFRGS e pelo Curso de Graduação Tecnológica - Planejamento e Gestão para o Desenvolvimento Rural da SEAD/UFRGS. - Porto Alegre: Editora da UFRGS, 2009. 120p.

GORGEN, S.A. Os novos desafios da Agricultura Camponesa. Porto Alegre: s/e, 2004.

GRIGORI, P. Governo liberou registros de agrotóxicos altamente tóxicos. Agência Pública / Repórter Brasil 2019. Disponível em: https://reporterbrasil.org.br/2019/01/governo-liberouregistros-de-agrotoxicos-altamente-

toxicos/?utm_campaign=shareaholic\&utm_medium=whatsapp\&utm_source=im. Acesso em 01 fev 2020.

HORT, J. V. Sustentabilidade E Saúde Pública: Relatos Médicos Sobre Patologias Associadas Ao Uso De Agrotóxicos - O Caso Do Município De Marechal Cândido Rondon - PR. Espaço Plural. Ano 17. n॰34. 1॰Semestre, 2016. P. 636-661. Disponível em: http://erevista.unioeste.br/index.php/espacoplural/issue/view/828/showToc. Acesso 10 out. 2016. 
LONDRES, F. Agrotóxicos no Brasil: um guia para ação em defesa da vida. Rio de Janeiro: ASPTA - Assessoria e Serviços a Projetos em Agricultura Alternativa, 2011.

MACHADO, E.P. Relação Entre Taxas de Mortalidade por Câncer e a Quantidade de Agrotóxicos teoricamente usada no Estado do Paraná. Dissertação de Mestrado. Curitiba, Universidade Federal do Paraná, 2007.

MASCARENHA, T. K. S. F. PESSOA, Y. R. S. Q. Aspectos Que Potencializam A Contaminação Do Trabalhador Rural Com Agrotóxicos: Uma Revisão Integrativa. Trabalho \& Educação, Belo Horizonte, v. 22, n. 2, p. 87-103, mai./ago. 2013. Disponível em: file:///C:/Users/Usu\%C3\%A1rio/Downloads/9061-Texto\%20do\%20artigo-26092-1-10-

20131004\%20(1).pdf. Acesso em: 01 fev. 2020.

MELLO, M.A. et al. Sucessão Hereditária e reprodução Social da agricultura familiar. Revista de Economia Agrícola. v. 50, n.1, p.11-24, 2003.

PARANÁ/SESA. Secretaria de Estado da Saúde do Paraná. Superintendência de Atenção à Saúde. Linha Guia da Atenção às Populações Expostas aos Agrotóxicos. - 1 ed. - Curitiba: SESA, 2018. 72 p. Disponível em: http://www.saude.pr.gov.br/arquivos/File/LinhaGuiaAgrotoxicos.pdf. Acesso 1 fev 2020.

PARANÁ. Governo do Estado. Secretaria de Saúde. Vigilância da Saúde de Populações Expostas à Agrotóxicos no Paraná. 2013. 142p. Disponível em: http://portalarquivos2.saude.gov.br/images/pdf/2015/setembro/02/PLano-PR.pdf. Acesso 01 fev, 2020.

PEREIRA, W.L. O que faz o enfermeiro na ESF: Estratégia Saúde da Família? IESPE, 2016 Disponível em: https://www.iespe.com.br/blog/o-que-faz-o-enfermeiro-na-esf-estrategia-saude-dafamilia/. Acesso em $01 \mathrm{fev} .2020$.

PIGNATTI W. Avaliação integrada dos impactos dos agrotóxicos na saúde e ambiente em Lucas do Rio Verde - MT, com ênfase na contaminação do leite materno. Comissão do Meio ambiente e Desenvolvimento Sustentável. Câmara dos Deputados. 3 jul, 2012.

RIGOTTO, M. R. et al. Uso de agrotóxicos no Brasil e problemas para a saúde pública. Cad. Saúde Pública, Rio de Janeiro, v.30, n.7, p.1-3, jul, 2014. Disponível em: http://www.scielo.br/pdf/csp/v30n7/pt_0102-311X-csp-30-7-1360.pdf. Acesso em 05 set 2018.

SARAIVA, A. M. P. O acesso à tecnologia em Saúde: Uma Perspectiva Bioética. Tese de Doutorado. Faculdade de medicina da universidade do porto, $1^{\circ}$ programa doutoral em Bioética. FMUP. Porto, 2015. 330p. Disponível em: file:///C:/Users/Usu\%C3\%A1rio/Downloads/Tese_ANA\%20MARIA\%20PINTO\%20SARAIVA\%2 0(2).pdf. Acesso em 15 mai. 2019.

SANTOS. M. GLASS, V. (organizadores). Atlas do agronegócio: fatos e números sobre as corporações que controlam o que comemos. Rio de Janeiro: Fundação Heinrich Böll, 2018. Disponível em: https://br.boell.org/sites/default/files/atlas_agro_final_06-09.pdf. Acesso 01 fev. 2020.

SIMÕES, U. A ameaça à saúde da população brasileira pelo uso indiscriminado de agrotóxicos. 2018. 105 f. Dissertação (Mestrado em Desenvolvimento Rural Sutentável) - Universidade Estadual do Oeste do Paraná, Marechal Cândido Rondon, 2018. Disponível em: http://tede.unioeste.br/handle/tede/3853. Acesso em 25 jun, 2020. 
Recebido em 01/02/2020 - Aprovado em 10/05/2020. 